\title{
O sujeito indígena subjetivado pela mídia na região do Mato Grosso do Sul
}

The indigenous subject subjectivized by the media in the region of Mato Grosso do Sul

\author{
Luiz Fernando Roecker ${ }^{1}$ \\ Universidade Federal da Grande Dourados - UFGD \\ luizfroecker1805@outlook.com \\ Sílvia Mara de Melo ${ }^{2}$ \\ Universidade Federal da Grande Dourados - UFGD \\ silviamelo@ufgd.edu.br
}

\begin{abstract}
RESUMO: Este trabalho objetiva discutir as representações midiáticas veiculadas em jornais, mídia local online, acerca dos sujeitos indígenas que vivem na região do Mato Grosso do Sul. Para sustentar nossas análises, buscamos o diálogo entre autores com pesquisas assentadas em Michel Foucault, empregando como referencial teórico a análise do discurso foucaultiana, bem como autores do campo epistemológico dos Estudos Culturais. O presente estudo revisita os conceitos de Sujeito, Enunciado, Discurso, Subjetividade em Fernandes $(2008 ; 2012)$ e em Foucault $(2002 ; 2006 ; 2008 ; 2011 ; 2014)$. Dialoga também com conceitos da Sociologia, não sendo possível esquecer o necessário resgate histórico quando se trata dos assuntos indígenas, trouxemos à baila o conceito de Estigma de Goffman (2019). Este trabalho também dialoga com as considerações acerca do Discurso Midiático de Charadeau (2013) e mais especificamente da mídia local e regional em Peruzzo (2005). Concluímos que os enunciados midiáticos acabam por reiterar e cristalizar a formação de imaginários estereotipados e estigmatizados a respeito dos povos indígenas.
\end{abstract}

Palavras-chave: Mídia Local; Sujeitos Indígenas; Subjetivação.

ABSTRACT: This paper aims to discuss the media representations published in newspapers and local online media about the indigenous subjects who live in the region of Mato Grosso do Sul. To support our analyses, we seek the dialogue among authors whose researches are based on Michel Foucault, we are using as theory foucaultiana analyses of speech as well as scholars of Cultural Studies. The present study revisits the concepts of Subject, Statement, Discourse, Subjectivity in Fernandes $(2008 ; 2012)$, and in Foucault $(2002 ; 2006 ; 2008 ; 2011 ; 2014)$. It dialogues with concepts of Sociology as well as Cultural Studies, not forgetting

\footnotetext{
${ }^{1}$ Acadêmico do $4^{\circ}$ ano do Curso de LETRAS da UFGD - Universidade Federal da Grande Dourados. Ao longo do período de graduação participou do PIBID - Programa Institucional de Bolsas de Iniciação à Docência, do PIBIC Programa Institucional de Bolsas de Iniciação Científica e atualmente faz parte do PIVIC - Pesquisa Voluntária e do PET - Programa de Educação Tutorial

${ }^{2}$ Possui graduação em Letras - Português/Inglês pela Universidade Estadual de Maringá, UEM (1998), mestrado em Letras pela Universidade Estadual Paulista Júlio de Mesquita Filho (2004) e doutorado em Linguística e Filologia da Língua Portuguesa - UNESP - Universidade Estadual Júlio de Mesquita Filho, Campus de Araraquara (2009). Atualmente é professora adjunta na Universidade Federal da Grande Dourados, UFGD, Faculdade de Comunicação Artes e Letras (FACALE). Tem experiência na área de Linguística, atuando principalmente nas áreas: análise do discurso, leitura e produção de textos, linguística. Integra o quadro de docentes do Programa de Pós-graduação em Letras da UFGD, área de Linguística e Transculturalidade; Estudos de Linguagem e Discurso.
} 
the necessary historical rescue when dealing with indigenous issues, and featuring Goffman's concept of Stigma (2019). This paper also discusses the considerations about the Media Discourse of Charadeau (2013) and more specifically the local and regional media in Peruzzo (2005). We conclude that the media statements end up reiterating and crystallizing the shaping of stereotyped and stigmatized imaginings regarding the indigenous peoples.

Keywords: Local Media; Indigenous Subjects; Subjectivation. 


\section{Introdução}

Esta pesquisa tem como base o método qualitativo-interpretativo, pois busca analisar e discutir as representações midiáticas acerca do sujeito indígena que habita o Estado de Mato Grosso do Sul - MS. Essas representações foram veiculadas em jornais digitais e impressos que possuem sede na cidade de Dourados, segunda maior cidade de Mato Grosso do Sul. Foram examinadas notícias e reportagens de dois jornais de grande repercussão local, a saber: Dourados News e O Progresso. O trabalho se mostra relevante por discutir e problematizar as representações dos sujeitos indígenas cristalizadas no imaginário social.

A escolha do tema se dá em virtude dos complexos conflitos culturais, econômicos e políticos envolvendo o sujeito indígena e o não indígena na região de Mato Grosso do Sul e mais especificamente da cidade de Dourados, onde ficam localizadas diversas aldeias indígenas. A pergunta de pesquisa que norteia nosso objeto de análise é: de que forma o sujeito indígena é representado pela mídia na região de Mato Grosso do Sul?

Para que o nosso olhar se volte para a os enunciados produzidos na contemporaneidade, é necessário fazer um resgate histórico referente ao tema, pois pensar a atualidade requer pensar os processos que a trouxeram aqui. É de conhecimento comum que os povos originários indígenas foram os primeiros habitantes do Brasil. De acordo com estudos revistados por Pagliaro, Azevedo e Santos (2005) e Azevedo (2008), existem estimativas que apontam a existência de cerca de 800 mil a 5 milhões de indígenas que habitavam o litoral ou interior do Brasil no início do século XVI, números que variam de acordo com os historiadores e os critérios utilizados em seus estudos. Passados 500 anos, a população indígena foi quase dizimada, chegando a menos de 100 mil na metade do século XX, segundo Azevedo (2008).

Nesse período, culturas, crenças, modos de viver, etnias e idiomas foram perdidos, terras e vidas indígenas foram retiradas em prol de uma "descoberta" do Brasil. O processo de colonização e de catequização ocorridos, no país, demarcam e talham a superfície da história do povo indígena, mas não os define. Atualmente, esse povo se depara com outros conflitos, alguns ainda resultantes do processo de colonização, e outros totalmente novos.

De acordo com o Censo Demográfico realizado pelo IBGE - Instituto Brasileiro de Geografia e Estatística -, detalhado em IBGE (2010), o país possuía cerca de 896,9 mil pessoas que se declaravam indígenas, apresentando grande crescimento em relação aos censos realizados anteriormente. Este crescimento não está relacionado apenas às taxas de natalidade, mas ao crescimento no número de pessoas que se reconhecem como indígenas. O Censo de 
2010 revela que o país possui 305 etnias e cerca de 274 línguas indígenas em toda a extensão territorial brasileira.

Segundo este mesmo Censo Demográfico, realizado em 2010, o Centro-Oeste ocupa a terceira posição de região com maior população indígena, sendo a região Norte a primeira. $\mathrm{O}$ Estado de Mato Grosso do Sul - MS ocupa a primeira posição com maior população indígena da região Centro-Oeste, com cerca de $56 \%$ da população indígena total dessa região, sendo 73.295 habitantes indígenas, ficando em segundo lugar dos Estados do Brasil com maior população indígena. O Censo revela que a cidade de Dourados ocupa o terceiro lugar com a maior taxa de domicílios indígenas de todas as cidades da Região Centro-Oeste, com cerca de 6.830 domicílios, a maior parte na área rural.

Em Dourados, há três aldeias denominadas de "Bororó", "Jaguapiru” e "Panambizinho", sem considerar os acampamentos de retomada que intencionam ser reconhecidos como terra indígena. A reserva indígena de Dourados possuía em 2014 cerca de 15 mil indígenas, número superior à da maioria das cidades do Estado, e a cidade conta com a presença das etnias Guarani, Guarani-Kaiowá, Guarani-Ñandeva e Terena.

Segundo Moura e Acçolini (2015), a etnia Terena atuou com protagonismo na constituição dos Estados de Mato Grosso e Mato Grosso do Sul. A história desse povo tem um marco significativo no contexto da Guerra do Paraguai (1864-1870), pois foi a partir de então que se deu o maior contato com os não indígenas, tendo sua dinâmica sociocultural atrelada à sociedade brasileira que se constituía. A etnia Terena lutou em defesa de seus territórios contra os paraguaios e, posteriormente, contra os próprios brasileiros, que se apossaram de suas terras após o término da guerra.

É importante reiterar que a não existência de processos de demarcação no período de pós-guerra era guiado por intenções diversas, desde a venda de terras à tentativa de uma assimilação do povo indígena à sociedade brasileira. Os Terena são um povo constituinte e constituidor da região do Mato Grosso do Sul, apesar de terem sido territorializados em pequenas reservas, e da tentativa de serem assimilados à sociedade brasileira objetivando um apagamento cultural, eles passaram a se mobilizar em prol do fortalecimento de suas identidades étnicas, resistindo e sobrevivendo, felizmente, até os dias atuais.

Segundo Chamorro (2015), o termo Guarani, referente à etnia e não apenas ao idioma, aparece designando povos indígenas diferentes dos Kaiowá, estes grupos já haviam sido descritos anteriormente, mas só em 1858 aparece o termo para precisá-los e diferenciá-los nos relatos de viagens exploratórias. A partir do que relata a autora, os dados permitem afirmar a clara diferenciação entre os Kaiowá e Guarani ainda no século XIX, mas essa separação é 
relativa, pois deve ser considerada a mistura e a união desses povos em diversos momentos. Houve maiores deslocamentos dos grupos Guarani e Kaiowá após o término da Guerra do Paraguai, pois os brasileiros brancos estavam retornando das fugas que realizaram no período de guerra e muitos outros estavam sendo enviados para ocupar a área segundo a política do presidente da província. Esses intensos deslocamentos dos grupos indígenas visavam encontrar áreas mais seguras, longe dos inúmeros postos militares ocupados por não indígenas.

Chamorro (2015) considera que o povo Guarani-Kaiowá tem sua história marcada pelo trabalho nos ervais desde o século XVII. A atividade de extração dos ervais afetou diretamente a forma de viver indígena, tendo suas formas de produção, consumo, sociabilidade e isolamento substancialmente alteradas. O regime de trabalho era análogo à escravidão, conforme descrito nas cartas de jesuítas da época. $\mathrm{Na}$ história dos povos originários indígenas Guarani-Kaiowá, houve diversos processos de dispersão, motivados principalmente pela ocupação de seus territórios, do pós-guerra, do trabalho nos ervais e da instalação de fazendeiros e colônias agrícolas. Desde então, seu modo de vida tem sido alterado cada vez mais, e o processo de reagrupamento/confinamento dos indígenas nas reservas modificaram profundamente as condições sociais, econômicas e ecológicas.

Os povos originários indígenas passaram por um processo de dispersão nos espaços geográficos motivados por diversos fatores. Nas últimas décadas, a demarcação de terras indígenas tem sido considerada um modo de busca e de garantia dos direitos indígenas, e também de reparação histórica. Apesar de o processo de aldeamento e demarcação de terras não repararem e não restituírem todas as grandes perdas desses grupos, o aldeamento tem sido um dos meios de garantir acesso às terras e aos recursos provindos dela, importantes para sua sobrevivência.

Considerando o exposto, e tendo como material de análise excertos de notícias locais, o trabalho tem intenção de dar destaque para questões indígenas contemporâneas e a forma como são veiculadas na mídia. Nosso estudo considera a importância da mídia local/regional, pois, além de ser considerada agente de disseminação de informação, detém significativa responsabilidade de mediar a construção da opinião pública e da formação de imaginários, contribuindo fundamentalmente com a construção dos papeis de representação social e de função social, promovendo debates, mediação de conflitos, propondo temas para discussão e reflexão. As mídias são consideradas instâncias que promovem valores, crenças, opiniões e informações. A escolha do jornal, e mais especificamente do jornal local, como fonte para 
análise, é justificada por crer que eles cumprem um papel social de tecer notícias da região e levantar pautas específicas de Dourados-MS.

O corpus deste estudo é constituído por enunciados retirados de notícias e reportagens que tratam de questões indígenas da contemporaneidade, e que foram veiculadas em jornais locais da cidade de Dourados entre os anos de 2018 a 2020, e para sustentar nossas análises, buscamos o diálogo entre autores foucaultianos, com pesquisas assentadas em Michel Foucault, bem como estudiosos dos Estudos Culturais. O trabalho na interface epistemológica se impõe por acreditarmos que noções de estigma/estereótipos são profícuas no campo teórico que foge da Análise do Discurso. Portanto, essa análise se inscreve no campo teórico da Análise do Discurso Foucaultiana e dos Estudos Culturais.

O presente estudo possui ancoragem nos conceitos de Sujeito, Enunciado, Discurso e Subjetividade em Fernandes (2008; 2012) e em Foucault (2008; 2011; 2014). Dialoga com conceitos da Sociologia e também dos Estudos Culturais, não sendo possível esquecer o necessário resgate histórico quando se trata dos assuntos indígenas, trazendo também o conceito de Estigma de Goffman (2019). Este trabalho também dialoga com as considerações acerca do Discurso Midiático de Charadeuau (2013) e mais especificamente da mídia local e regional em Peruzzo (2005). Para isso, iremos nos debruçar sobre a teoria para, posteriormente, partir para a análise dos dados.

\section{Discurso e sujeito: nas tramas do discurso}

A Análise do Discurso foi fundada pelo filósofo francês Michel Pêcheux e pelo linguista Jean Dubois no final da década de sessenta. Segundo Melo (2009), este é o período em que as novas teorias Linguísticas apontavam um rompimento para com os estudos estruturalistas, introduzindo, na época, a preocupação com fatores do funcionamento da linguagem em uso e de mecanismos próprios à enunciação, fazendo com que a concepção de língua e de como analisá-la sofressem alterações. O sentido passaria a ser pensado não apenas ligado ao sistema linguístico e sua forma, mas ao seu uso, introduzindo a dimensão social. Essa disciplina tem o discurso como principal objeto de estudo científico, sendo a Linguística um dos campos de estudo que se interseccionam com Materialismo Histórico e a Psicanálise para formar as diferentes áreas do conhecimento que são utilizadas nos estudos da Análise do Discurso, doravante $\mathrm{AD}$. As recorrências a essas áreas de modo interdisciplinar têm como intenção apreender o discurso por meio da língua, o sujeito e a história. 
A $\mathrm{AD}$ é uma corrente de estudos que foi desenvolvida inicialmente na França e que privilegia o estudo das Condições de Produção, bem como os efeitos de sentido dos enunciados, considerando as relações de poder e das lutas sociais que faziam e fazem parte da vida de todos os indivíduos. Partindo da análise das estruturas linguísticas construídas nos processos de interação e por meio de uma recorrência à História e ao Sujeito, a $\mathrm{AD}$ se preocupa em evidenciar os discursos constitutivos e constituidores dos enunciados. Assim, a língua é considerada um lugar privilegiado em que as ideologias se materializam, utiliza-se componentes linguísticos e componentes sócio-históricos-ideológicos para servir como norte para a análise dos discursos.

Dessa forma, a AD percebe os discursos vinculados às Condições de Produção em que foram gerados e considera o Sujeito enunciador, e a posição ocupada por ele, como fundamental no processo de construção dos sentidos e de significações. A teoria discursiva como disciplina surge em meio aos conflitos gerados por tensão social e política. A produção e recepção textual passaram a ser incorporadas nas análises linguísticas que, até então, eram estritamente estruturalistas. Após esta breve introdução da disciplina da Análise do Discurso e de seu surgimento, passaremos aos conceitos de Discurso, Enunciado e de Sujeito, fundamentais à área.

O discurso, neste caso, é pensado como um conceito abstrato, e não apenas como um pronunciamento político ou religioso em um palanque ou altar, conforme geralmente é concebido. Para compreendermos a noção de discurso, é necessário considerá-lo como algo exterior à língua, o discurso não é a língua, não é um texto ou um debate cheio de usos rebuscados com construções complexas, mas o discurso é materializado na e pela língua. Conforme concebe Fernandes (2008), o discurso é materializado através de elementos linguísticos nos enunciados e nos textos verbais e não-verbais. A todo momento, quando um sujeito faz uso da linguagem, está evocando termos, palavras e expressões carregadas de símbolos ideológicos e históricos, que marcam a posição desse sujeito que enuncia.

$\mathrm{Na} \mathrm{AD}$, se faz necessário considerar não apenas o aspecto linguístico, pois é no exterior da estrutura da língua que os sentidos dos enunciados e das palavras são gerados e apreendidos. Não é a partir de uma análise fonológica, morfológica ou sintática que se encontra o discurso constitutivo dos enunciados, porém cada uma dessas áreas, importantes para o estudo do funcionamento interno da língua, só são relevantes para a $\mathrm{AD}$ quando afetarem o campo da constituição dos sentidos. Se existem posicionamentos conflitantes e embates divergentes, eles estarão expressos nas construções linguísticas e semióticas geradas nos processos de interação. Desse modo, para que se possa pensar o discurso, faz-se 
necessário considerar as Condições de Produção dos enunciados, pois conforme propõe Fernandes, "a noção de discurso implica considerar as condições histórico-sociais da produção que o envolvem e determinam-no" (FERNANDES, 2012, p. 16). Ou seja, para pensá-lo e analisá-lo, é necessário retomar o momento de produção dos enunciados, o momento histórico que ele faz parte, a localidade e quem pronunciou, tudo o que faz parte da enunciação. Dessa forma, a análise não se detém apenas na estrutura dos enunciados linguísticos, classificando as palavras em verbo ou adjetivo, conforme suas classes gramaticais, mas considera a historicidade, por entendermos que são constituidoras de sentido e de significação.

Ao propor o conceito de Enunciado, Foucault (2008) estabelece uma série de negativas acerca do conceito; o enunciado não se relaciona com intenção do sujeito que enunciou e nem do que foi alcançado com a enunciação, não se refere ao ato material de falar ou escrever, mas se refere à "operação que foi efetuada [...] o que se produziu pelo próprio fato de ter sido enunciado, e precisamente esse enunciado e nenhum outro" (FOUCAULT, 2008, p. 94), e ainda acrescenta que "qualquer série de signos, de figuras, de grafismos ou traços são suficientes para constituir um enunciado". (FOUCAULT,2008, p. 95).

Para Foucault (2008), o enunciado e a língua não estão no mesmo nível de exigência, não sendo o enunciado do mesmo gênero da frase ou da proposição, não será dividindo a frase em diversos elementos menores que se chegará ao enunciado. Dito isso, o autor complementa que "o enunciado não é, pois, uma estrutura [...], é uma função de existência que pertence, exclusivamente, aos signos" (FOUCAULT, 2008, p. 98). Busca-se na exterioridade as regras de sua aparição, sempre havendo uma posição-sujeito na intenção de apreender sua materialidade no tempo e no espaço, referente às condições de produção do enunciado. Sobre o mesmo conceito, Fernandes (2012, p. 26) assegura que "os enunciados, assim como os discursos, são acontecimentos suscetíveis de serem analisados considerando a continuidade, a descontinuidade, a dispersão, a formação e a transformação". Neste trabalho, o foco recai sobre os enunciados construídos acerca dos sujeitos indígenas na região de Dourados - MS, dispostos na seção de análise.

A noção de discurso é apreendida sempre considerando o aspecto social, como aquilo que permeia todas as relações sociais, todo e qualquer processo interativo, não ficando de fora as lutas de/por poderes, militâncias e ativismos. Desse modo, é necessário compreender os aspectos históricos-sociais envolvidos nas condições de produção dos discursos. Um discurso é constituído de tudo o que tem vida social, as mudanças históricas, as decisões políticas e religiosas, as alterações advindas do saber científico, novas concepções e, em contraposição, o 
que foi dado como falso quando uma nova teoria passou a ter valoração, tudo isso faz parte da constituição de um discurso.

Foucault (2014) propõe que o discurso da medicina e da botânica são feitos tanto de erros como de verdades, em que os erros têm funções positivas, como uma eficácia histórica. Assim, o discurso não é tido como homogêneo, fixo e imutável, pelo contrário. A compreensão de discurso, na $\mathrm{AD}$, sugere as idas e vindas, contornos e movências dentro de um mesmo discurso. Corroborando essa assertiva, Fernandes defende que na "acepção foucaultiana, todo discurso é marcado por enunciados que o antecedem e o sucedem e caracteriza-se pela contradição" (FERNANDES, 2012, p. 24).

Assim como é necessário considerar a história e o aspecto social na concepção de Discurso, temos o movimento inverso, o Discurso sendo importante para a compreensão das transformações históricas e sociais:

o discurso apresenta-se relevante para compreender as mudanças históricas e sociais que possibilitam a combinação de diferentes discursos em certas condições sociais específicas, resultando na produção de outros discursos. $\mathrm{O}$ aspecto histórico decorre das transformações sociais entre sujeitos e grupos de sujeitos como um movimento ininterrupto e descontínuo na linha do tempo, que conduz para a constituição de outros sujeitos e outros grupos sociais, bem como para a formação de novos discursos (FERNANDES, 2012, p. 24).

Tendo isso em vista, os aspectos políticos e sociais são e devem ser considerados na $\mathrm{AD}$, pois estão presentes na relação entre todos os sujeitos. Entendemos que as mudanças culturais, sociais e políticas corroboram com o jogo de dispersão e aparecimentos dos discursos, que são transformados sincrônica e diacronicamente.

Uma mesma palavra pode ser geradora de sentidos diferentes, a depender da inscrição sócio-ideológica dos sujeitos envolvidos no processo de interação. Como exemplo prático, citamos o estudo de Fernandes (2008) que dispõe sobre os usos dos substantivos ocupação e invasão nas situações de luta por terras do Movimento Sem-Terra (MST). Ambas as palavras eram usadas para uma mesma ação, porém cada uma sendo constitutiva de discursos contrários; ocupação sendo usada pelos sem-terra e apoiadores, e invasão, pelos que eram contrários a essa ação, geralmente "donos" de terras. Os sentidos dessas expressões são gerados em condições de produção específicas, com tempo e espaço precisos. Nesse sentido, o autor considera que "os discursos, por sua vez, obedecem a determinações históricas; é a história que lhes assegura condições de possibilidade" (FERNANDES, 2012, p. 22).

Foucault, estudioso do discurso, apresenta a seguinte hipótese: 
Suponho que em toda sociedade a produção do discurso é ao mesmo tempo controlada, selecionada, organizada e redistribuída por certo número de procedimentos que têm por função conjurar seus poderes e perigos, dominar seu acontecimento aleatório, esquivar sua pesada e temível materialidade (FOUCAULT, 2014, p. 8-9).

Foucault, autor do livro A ordem do discurso, elaborado a partir de sua aula inaugural no Collège de France, pronunciada em 2 de dezembro de 1970, discorre sobre como o discurso é controlado e organizado, apresentando tipos de procedimentos internos e externos de delimitação e controle do discurso. Fernandes (2012) considera que esses procedimentos requerem compreender que discurso é considerado como prática, que envolve sujeitos e situações de enunciação, e que as especificidades de cada situação impõem regras aos sujeitos do discurso. Esses procedimentos de exclusão para com a produção e controle dos discursos, se complementam, se reforçam e se cruzam com base no modo como a sociedade está organizada. Foucault (2014, p. 9) defende que "nem todo mundo pode dizer qualquer coisa e em qualquer lugar e qualquer circunstância”, justamente pela operação desses procedimentos de exclusão. E aponta que as regiões da política e da sexualidade são as áreas com as "grades mais cerradas". Deste modo, as análises de discursos intentam chegar a uma "compreensão da produção de discursos, em seu aparecimento e dispersão" (FERNANDES, 2012. p. 20).

Para Fernandes (2012, p. 17), a leitura da obra de Foucault amplia a abrangência da $\mathrm{AD}$, pois para ele "o discurso é uma categoria fundante do sujeito, do saber, do poder, da verdade, da subjetividade". Ainda sob a perspectiva desse autor, o discurso "está em uma relação direta com o sujeito, como o que o constitui, ou o produz, e em relação direta com a história, visto que é a história que determina/possibilita a existência do discurso" (FERNANDES, 2012, p. 18). Na Análise do Discurso, pensar discurso requer que se considere o sujeito.

A partir do que diz Fernandes (2008), o sujeito, conceito fundamental nos estudos dos mecanismos discursivos, é apreendido como heterogêneo, descentrado e não como um ser humano individualizado, pelo contrário, é concebido dentro de uma coletividade, no espaço social, marcado histórica e culturalmente. Sua posição revela diversas vozes sociais, e por vezes essas vozes podem se contradizer ou se complementar. Para Fernanda Mussalim (2009), os estudos realizados por Freud sobre o inconsciente contribuiriam para que a noção de sujeito viesse a ser ressignificada, pois a visão de sujeito homogêneo, inteiro e completo passaria a "ser questionada diante da concepção freudiana de sujeito clivado, dividido entre o consciente e o inconsciente" (MUSSALIM, 2009, p. 107). 
Fernandes (2008) discorre sobre como a noção de Sujeito era concebida nos estudos linguísticos:

Na Linguística, em geral, o sujeito quando considerado, ora é idealizado, ora é um sujeito falante, apreendido em um contexto social imediato. Para o sujeito idealizado (ideal e não real), trabalha-se com uma concepção de língua como algo abstrato, um dispositivo que o sujeito, nesse caso indivíduo, poderá apreender e, consequentemente, tornar-se usuário (FERNANDES, 2008, p. 25).

O sujeito compreendido desta maneira é um sujeito empírico, individualizado e que tem a capacidade para aquisição da língua e a utiliza em conformidade com o contexto, entendido como sujeito falante. Nesse modo de conceber o sujeito, se perde muito do sujeito e de sua função, pois há um apagamento da (rea)ação do sujeito no uso da linguagem.

Contrariando tal concepção, Fernandes (2008) considera que o Sujeito, ou Sujeito Discursivo, deve ser considerado como um ser social em um espaço coletivo, e que sua voz revela o espaço social ocupado por ele, e ainda expressa um conjunto de outras vozes integrantes dessa realidade histórica e social. O sujeito "não é homogêneo, seu discurso constitui-se do entrecruzamento de diferentes discursos, discursos em oposição, que se negam e contradizem" (FERNANDES, 2008, p. 26). Falar em sujeito discursivo pede a compreensão de quais são as vozes sociais que fazem presente em sua voz. Fernandes (2012) defende que "o sujeito, por sua vez, é constituído por discursos historicamente produzidos e modificados; assim como o discurso, o sujeito está em constante produção, é marcado por movências e constituído pelos discursos" (FERNANDES, 2012, p. 16).

$\mathrm{Na}$ primeira e segunda fases da $\mathrm{AD}$, o conceito de Formação Discursiva tinha maior espaço, mas com o desenrolar dessa disciplina, as questões e reflexões passaram a centrar-se no conceito de sujeito. O sujeito discursivo passou a ser compreendido como "um lugar sóciohistórico discursivamente produzido, heterogêneo e plural, sempre em processo de constituição" (FERNANDES, 2012, p. 16).

A partir das considerações de Sathler (2016), o conceito de Sujeito considerado como um ser único e individual no mundo e que assume uma posição e ali permanece perde força e passa a ser visto como uma construção que vai se fazendo aos poucos, por apropriações, unificações e agregações. Passa a ocupar posições-sujeito, apreendido em um lugar momentaneamente e que logo já é outro, descontínuo e disperso, apesar de sua tentativa de ser regular.

Fernandes (2012, p. 18) aponta que o "o discurso é aquilo que promove a produção da subjetividade, sendo o sujeito um efeito da subjetividade". Essa concepção ganha espaço na 
terceira fase dos estudos de Foucault, denominada de Ética ou Estética da Existência, em que o conceito de sujeito implicará pensar em subjetividade, visto que o sujeito é construído no processo de subjetivação.

Michel Foucault considera que o discurso, inicialmente exterior aos Sujeitos, mas se revelando também como aquilo que os constituem, atua fortemente na produção das subjetividades. Nas palavras de Foucault (2006, p. 394), "é para que ele possa vir a integrar-se ao indivíduo e comandar sua ação, fazer parte de certo modo de seus músculos e nervos". Dessa forma, ele, o discurso, constitui e produz subjetividades, e consequentemente sujeitos.

Esses autores concebem que os sujeitos são constituídos no processo de subjetivação, que, por sua vez, é moldada pelos discursos, vivências, experiências, crenças e práticas sociais, ou seja, por tudo o que lhe é exterior. Desse modo, subjetividade, sujeito e discurso possuem intrínseca relação, pois cada um ocasiona a produção do outro, como um processo de dependência.

Este processo complexo de subjetivação "consiste justamente no processo constitutivo dos sujeitos, pela produção da subjetividade que possibilita, em acepção foucaultiana, a objetivação dos sujeitos [...], os modos de subjetivação produzem sujeitos singulares" (FERNANDES, 2012, p. 74).

Desse modo, os sujeitos são considerados posições-lugares em uma linha descontínua, além disso, as construções de seus enunciados revelam seus discursos e as posições ocupadas por ele. A linguagem é o recurso tido como ponto mais próximo de apreender os sujeitos. As subjetividades são produzidas pelo exterior, mas também é reveladora do interno e do íntimo, pois "no homem, o interior é também o exterior, de que o ponto extremo da subjetividade se identifica com o fascínio imediato do objeto" (FOUCAULT, 2002, p. 511).

A subjetividade, "vista da exterioridade, apresenta-se como uma construção histórica sob determinadas condições e se dá na relação com o discurso" (FERNANDES, 2012, p. 76). Os mecanismos de construção da subjetividade funcionam em consonância com os discursos aos quais o sujeito tem contato. Por isso, a subjetividade remete a uma exterioridade, pois sua construção se baseia nos diferentes discursos, que só podem ser pensados socialmente e historicamente. O sujeito é considerado como aquele que não decide sobre os sentidos e as possibilidades enunciativas do próprio discurso, mas como aquele que ocupa uma posição em dada formação social e que a partir dela enuncia. Porém, os sujeitos transitam por diversas formações sociais e ocupam os lugares que lhes cabem ali, de acordo com as regras previstas. O sujeito não é livre para dizer o que quer e onde quer, mas é levado a dizer e reproduzir determinadas construções enunciativas. Sem que tenha consciência, ele é levado a enunciar o 
que é possível desse lugar que ocupa, e, desse modo, o discurso, manifestado nos enunciados, revela uma posição-sujeito marcada social e historicamente.

Fernandes (2008) pontua que os sujeitos estão colocados em relações de poder muito complexas, e considera que as relações de poder são importantes para a disciplina da AD porque "os enunciados apontam para posições-sujeitos, e essas posições são marcadas por relações de poder que se opõem. O poder coloca em jogo relações entre sujeitos e os discursos refletem os lugares desses sujeitos" (FERNANDES, 2008, p. 59).

Ao considerar que os sujeitos indígenas na região do Mato Grosso do Sul são subjetivados por uma historicidade constituída por notícias recorrentes na mídia, vejamos como a noção de estigma/estereótipo se apresenta como um modo de subjetivação desses povos.

\section{Estigma}

Recorremos a Goffman (2019) para problematizar a noção de estigma e estereótipo, pois, segundo ele, a sociedade estabelece e dita os meios de categorizar as pessoas e os atributos que elas devem possuir para fazerem parte desta ou daquela categoria. Os ambientes sociais estabelecem as categorias de pessoas que neles são previsíveis de serem encontradas. As rotinas das relações sociais, por sua vez, condicionam que as relações aconteçam com pessoas já previstas naquele espaço social, sem atenção ou reflexão particular. Nesse cenário, são geradas expectativas, normas e diretrizes a serem seguidas ou esperadas naquele ambiente, de modo bastante rigoroso.

Em uma dada situação, em que um indivíduo "estranho" aparece nesse quadro previamente "organizado", de imediato, os primeiros aspectos permitem prever a categoria a que ele pertence, de acordo com seus atributos, ou seja, sua identidade social. Porém, essas exigências são ignoradas até que surja uma questão efetiva de reflexão a respeito delas, entrando em discussão os conceitos de estigmas e estereótipos.

Para Goffman (2019, p. 6),

O termo estigma, portanto, será usado em referência a um atributo profundamente depreciativo, mas o que é preciso, na realidade, é uma linguagem de relações e não de atributos. Um atributo que estigmatiza alguém pode confirmar a normalidade de outrem, portanto ele não é, em si mesmo, nem horroroso, nem desonroso. 
O estigma é considerado como uma característica que não está no quadro de expectativas esperadas. Nas palavras de Goffman (2019, p. 8), "ele possui um estigma, um traço ou uma característica que não havíamos previsto". Cada sociedade define categorias de atributos que são esperados, considerados naturais e comuns, é claro que nem todos os atributos estão em jogo o tempo todo, apenas aqueles que confrontam com o do estereótipo criado previamente. E o autor acrescenta: "um estigma, é então, um tipo especial de relação entre atributo e estereótipo". (GOFFMAN, 2019 p. 7). O estigmatizado é aquele indivíduo que poderia ter sido facilmente recebido na relação social cotidiana, mas que possui um traço que se pode impor a atenção e afastar aqueles que o encontra, deixando de lado a possibilidade de atenção para outros atributos seus. As ações em resposta a essa situação social, de modo benevolente, são as tentativas de suavizar e melhorar a situação da pessoa estigmatizada. Por outro lado, essas situações nem sempre são apenas encaradas de modo positivo ou neutro, mas:

Com base nisso, fazemos vários tipos de discriminações, através das quais efetivamente, e muitas vezes sem pensar, reduzimos suas chances de vida: construímos uma teoria do estigma; uma ideologia para explicar a sua inferioridade e dar conta do perigo que ela representa, racionalizando algumas vezes uma animosidade baseada em outras diferenças, tais como as de classe social. Utilizamos termos específicos de estigma como aleijado, bastardo, retardado, em nosso discurso diário como fonte de metáfora e representação, de maneira característica, sem pensar no seu significado original (GOFFMAN, 2019, p. 8).

Os indígenas são constantemente estigmatizados, encontram-se no limiar de culturas, crenças e identidades, que se esbarram e se transformam no contato de uma com a outra. Os povos indígenas acabam por presenciar discursos preconceituosos, eles são comumente rotulados de "primitivos", "sujos", "malvestidos", e até mesmo de "vagabundos", imagens que vão sendo paulatinamente cristalizadas no imaginário social e que vem à tona quando se fala deles. Considerando que as mídias também ressaltam e corroboram esses estereótipos, compreendemos ser relevante abordarmos suas funções e papeis na sociedade.

\subsection{Mídia: função social ou cristalização de estigmas?}

Nossa análise se debruçará em enunciados veiculados pela mídia; por isso, consideramos importante tecer considerações a respeito do funcionamento deste veículo.

Patrick Charaudeau (2013), em seus estudos sobre os discursos midiáticos, aponta que as mídias funcionam com base, no mínimo, em três lógicas - econômica, tecnológica e 
simbólica. A primeira se dá porque agem como uma empresa, fabricando um produto (a informação) a ser vendido para um consumidor. A segunda se refere às recentes demandas, de terem que estender a qualidade e quantidade de suas informações envolvendo meios tecnológicos. E, por último, a lógica simbólica, que está relacionada a todo organismo de informação atuar na construção da opinião pública e servir à democracia cidadã.

Charaudeau (2013) considera que as lógicas econômicas e tecnológicas são incontornáveis, mas que é a lógica simbólica que interessa para seu trabalho pois, além de governar as demais, "trata-se da maneira pela qual os indivíduos regulam as trocas sociais, constroem as representações dos valores que subjazem as suas práticas, criando e manipulando signos e, por conseguinte, produzindo sentido" (CHARAUDEAU, 2013, p. 16). Ele ainda acrescenta que as mídias buscam tornar público aquilo que geralmente seria ignorado, oculto ou secreto, prestando, assim, um serviço em benefício da cidadania e da democracia.

Porém, as mídias também são regidas por lógicas comerciais e concorrem com outras empresas que têm a mesma finalidade, tentam captar e se dirigir ao maior público possível, preocupando-se em como vender mais, considerando as incontornáveis regras mercadológicas. Em alguns casos, são gerados espetáculos sensacionalistas, mostradas imagens da miséria humana, além de notícias falsas e tendenciosas, pois selecionam o que é mais surpreendente, tentam tornar "visível o invisível", acusam e condenam, e por vezes ignoram o princípio da presunção de inocência - de que ninguém é culpado até que se prove o contrário.

Por estes motivos, segundo o autor, sua atividade pode "tornar-se suspeita porque sua finalidade atende a um interesse diferente do serviço da democracia" (CHARAUDEAU, 2013, p. 59) e que a recorrência apelativa das mídias "nem sempre atende à exigência de credibilidade que lhe cabe na função de serviço ao cidadão" (2013, p. 59). Nesse sentido, é construída "uma imagem fragmentada do espaço público, uma visão adequada aos objetivos da mídia, mas bem afastada de um reflexo fiel" (CHARAUDEAU, 2013, p. 20).

Surge a dualidade entre captar o público ou ter credibilidade, quando tendem para o segundo, em um aspecto austero e racionalizante, não tocam o público, e quando tendem para o primeiro, dramatizante e apelativo, menos credíveis são. De todo modo, é claro que esses motivos não são suficientes para ignorarmos a preocupação e o estudo dos mecanismos midiáticos, pois o próprio autor pontua que as mídias "regulam o sentido social ao construir sistemas de valores" (CHARAUDEAU, 2013, p. 17). 
Se faz relevante para nossa pesquisa pensar o papel das mídias locais e regionais: de sua função e de seus problemas. Segundo Peruzzo (2005), o advento da globalização chegou a lançar dúvidas se a mídia local passaria por um processo de supressão e apagamento, porém se revelou o contrário, “a revalorização da mesma, sua emergência ou consolidação em diferentes contextos e sob múltiplas formas" (PERUZZO, 2005, p. 4). Anterior à década de 1990, as grandes redes de comunicação no Brasil tendiam a concentrar-se nos grandes centros e a produzir notícias apenas sobre estes locais. Passaram a valorizar, tardiamente, os meios de comunicações locais e fizeram isso baseando-se mais em questões mercadológicas do que de produção de conteúdo regionalizado.

A mídia local tem sua ancoragem estabelecida na produção de notícias geradas no território ao qual pertence, perpassada pela familiaridade e singularidade de cada região, e que, em tese, retrata a realidade local e regional, trabalhando com informação de proximidade. De acordo com Peruzzo (2005, p. 10), “os conteúdos são aqueles que encontram pouco ou nenhum espaço na grande mídia. Em geral, abordam assuntos que afetam diretamente a vida das populações em seu local de moradia e na vida cotidiana, a partir da mobilização social”.

No jornalismo local, existe a possibilidade de mostrar a região, o município, o bairro ou o distrito ou zonal rural melhor do que qualquer outro jornal poderia fazê-lo, exatamente porque a informação está próxima tanto da instância de produção quanto da instância de recepção, contribuindo com temas locais. Esse tipo de jornalismo

está num contexto vantajoso para o leitor ou telespectador, ou seja, a proximidade da informação. As pessoas acompanham os acontecimentos de forma mais direta, pela vivência ou presença pessoal, o que possibilita o confronto entre os fatos e sua versão midiática de forma mais natural (PERUZZO, 2005, p. 12).

Porém, existem alguns problemas neste tipo de jornalismo; segundo a autora, há certa tendência com o jornalismo local e regional, como, por exemplo: os laços políticos tendem a ser mais fortes, podendo comprometer a informação de qualidade, não necessariamente laços político-partidários, mas com quem está no exercício do poder. É comum a existência de tratamento tendencioso da informação e até a omissão de fatos, em decorrência de ligações políticas com os detentores do poder local e dos interesses econômicos de donos da mídia. Há ainda a preocupação com a reprodução integral e acrítica de notícias veiculadas por outros jornais. Outra tendência é a falta de ampla cobertura e de apuração de acontecimentos, tanto no nível local como no regional. Isso se deve a uma estrutura de produção pequena, com poucos profissionais e, às vezes, até despreparados para o exercício do jornalismo. Há 
situações em que as informações advindas diretamente de assessoria de imprensa do legislativo ou executivo não possuem tratamento e mediação, apenas são reproduzidas integralmente na mídia. A autora considera que "nessas condições o jornalismo local deixa de explorar seu imenso potencial de trabalhar com a informação isenta e atender a todos os setores que perfilam a vida de uma comunidade" (PERUZZO, 2005, p. 15).

Peruzzo (2005, p. 15) considera que a mídia local, também nomeada de mídia de proximidade ou regional, deve caracterizar-se "por vínculos de pertença, enraizados na vivência e refletidos num compromisso com o lugar e com a informação de qualidade e não apenas com as forças políticas e econômicas no exercício do poder”.

A mídia é considerada agente de disseminação de informação, detém significativa parcela do poder de mediar a formação da opinião pública e de imaginários sociais, contribuindo fundamentalmente com a construção dos papeis de representação social e de função social, promovendo debates, mediando de conflitos, propondo temas para discussão e reflexão.

Considerando que nosso corpus de pesquisa se constitui de enunciados de mídias locais, vejamos a seguir como os jornais locais trazem matérias relacionadas às questões indígenas na cidade de Dourados e da região do Mato Grosso do Sul.

\section{A mídia e as questões indígenas na região do Mato Grosso do Sul}

A escolha do jornal como fonte para análise é justificada por crermos que os jornais cumprem um papel social de transmitir informações, de influenciar a formação de opiniões, de promover debates e discussões, de mediar conflitos e também de levantar pautas específicas da cidade de Dourados e da região do Mato Grosso do Sul. Os recortes selecionados para compor esta análise se dão no espaço temporal da contemporaneidade, de acontecimentos e eventos recentes (2018-2020), e se justifica por ainda nos depararmos com situações de extrema vulnerabilidade dos povos indígenas que, por centenas de anos, vêm sofrendo agressões físicas e verbais, e boa parcela da sociedade brasileira, de modo geral, ainda não se mostra sensibilizada e motivada a compreender os complexos conflitos que levam os sujeitos indígenas a viverem situações de pobreza e risco de vida iminentes. 


\subsection{Vulnerabilidade indígena}

Atualmente, um dos problemas enfrentados pelos povos indígenas é a falta de garantia de posse às terras que tradicionalmente habitavam. É importante reiterar que os povos indígenas já habitavam essas terras, que foram, na maioria dos casos, ocupadas pelos fazendeiros e agricultores com apoio de lideranças políticas e militares, do emergente Estado. E ao longo do tempo, os indígenas foram obrigados a se estabelecerem em regiões cada vez menores, numa espécie de confinamento em aldeias e reservas indígenas, sendo que a maioria delas foram demarcadas no período de 1915 e 1928, conforme aponta Chamorro (2015), ou seja, a quase um século, e apesar das dimensões territoriais continuarem as mesmas, o crescimento da população indígena é significativo. O desmatamento com fins econômicos, seja para produção madeireira, para plantio ou para servir de pasto para gado, fez com que a paisagem natural fosse totalmente devastada. Resultante desse processo, a região de Dourados ficou conhecida por seu poder econômico provindo das atividades de agropecuária.

Os padrões culturais das etnias e das tribos indígenas não ficaram intocados, a identidade cultural, os costumes, as vestimentas, crenças e também a ligação com a terra e a natureza passaram por mudanças drásticas motivadas por esse processo colonizador. Apesar do choque cultural e identitário ser previsto no contato de diferentes culturas, nas situações em que a cultura hegemônica se mantêm dominante e supervalorizada, a outra, a indígena e a de povos minoritários, continua sendo discriminada. Os preconceitos e as discriminações não são expressos e materializados apenas no nível da linguagem, mas em ações cotidianas de descaso, violência e negação de direitos. Os corpos indígenas que manifestam essas culturas e identidades são punidos e violentados, visto que esse contato de diferentes culturas nem sempre dá de modo pacífico e respeitoso, muito pelo contrário, é imposto violentamente.

A seguir, lemos dois enunciados veiculados pelas mídias locais da cidade de Dourados-MS.

\section{Enunciado 1}

Reserva de Dourados tem maior taxa de suicídio do país (Jornal Dourados News elaborado em parceria com o Ministério Público Federal, 09 de janeiro de 2018)

\section{Homicídios e suicídios}

A violência no local é outro ponto a se destacar. Com base nos dados oficiais, entre 2012 e 2014, o Brasil teve taxa média de 29,2 homicídios por 100 mil habitantes. Em Mato Grosso do Sul, a taxa foi de 26,1. Entre os indígenas de MS, 
este número sobe para 55,9. Já os indígenas da Reserva de Dourados enfrentam uma taxa de homicídios de 101,18 por cem mil habitantes. Os indígenas da região morrem por homicídio a uma taxa quase $400 \%$ superior aos não indígenas de MS. Fator negativo também em relação ao suicídio entre os indígenas da etnia guaranikaiowá. Em 2015, enquanto a taxa brasileira foi de 9,6 suicídios por 100 mil habitantes, a mesma taxa entre os indígenas foi de 89,92, número que não encontra paralelo nem entre os países com maiores índices do mundo. A maioria das mortes ocorreu na faixa dos 15 aos 29 anos.

Mais violência

A violência se repete também com relação a outros crimes, como a violência doméstica e sexual. Relatório oficial do Distrito Sanitário especial Indígena (DSEI/MS) revela que os determinantes sociais impactam diretamente na saúde: "A precariedade da segurança pública, educação deficitária, alimentação e habitação inadequadas, carência de projetos voltados para a geração de renda e emprego e a ausência de políticas públicas para os indígenas refletem no alto indice de violência, consumo de drogas e álcool, mortalidade infantil e os alarmantes índices de homicídio e suicídio”. Em relação a crianças e adolescentes acolhidos em instituições estatais na região de Dourados, a disparidade é a mesma. Em 2016, foram internados 410 adolescentes não indígenas e 282 indigenas. Embora representem apenas 6,79\% da população de Dourados, os indígenas responderam por $67 \%$ das internações, o que mostra que a violência atinge esta população de forma particularmente intensa.

\section{Enunciado 2}

\section{Em aldeia mais perigosa do País para mulheres, força indígena se une contra violência doméstica (Jornal O Progresso - Valéria Araújo, 04 de dezembro de 2019)}

Enquanto isso, a segunda maior cidade sul-mato-grossense segue com dados alarmantes: além de figurar como o segundo município brasileiro com os maiores registros de todos os tipos de violência contra as mulheres indígenas, lidera o ranking do abuso sexual contra elas no país, com 31 casos em 2017. Eles são cerca de metade de todas as ocorrências registradas no Estado naquele ano. Desde 2012, é a cidade onde mais mulheres indígenas são vítimas de violência sexual no Brasil. De acordo com o Ministério Público Federal, há uma discriminação das autoridades no tratamento a população indigena. Conforme a Procuradoria informou em recente encontro com lideranças, se um crime é cometido dentro dos limites de uma Aldeia ou Reserva Indígena, seja roubo, furto, violência doméstica ou assassinato, os moradores não encontram respaldo junto às autoridades policiais que, na maioria das vezes, ignoram o chamado alegando falta de combustível, de viatura, de efetivo ou até mesmo falta de segurança.

O enunciado 1 apresenta dados comparativos de homicídios e suicídios, descrevendo a situação desproporcionalmente negativa desses casos em relação aos indígenas. $\mathrm{O}$ enunciado 2 apresenta mais dados significativos a respeito da violência presente na Reserva, 
denunciando também a falta de prestação dos serviços públicos de proteção, que acaba por ampliar os dados. Estes dois enunciados, trechos retirados de notícias maiores, apresentam uma parcela dos problemas enfrentados pelos moradores da Reserva Indígena de Dourados. Ambas as notícias revelam dados estatísticos sobre os crimes de homicídio, de suicídio, de violência sexual, além de enumerar problemas gerados pela falta de ação das instituições públicas para com esses povos, instituições essas que deveriam promover acesso a segurança, saúde e educação.

Estas notícias cumprem, pelo menos inicialmente, o papel da mídia de informar, fazer a mediação dos dados, de "dar voz a quem não pode falar", gerando um sentimento de comoção para com os indivíduos que estão inseridos nesse cenário bastante violento, mas também constroem outros imaginários. A partir dos enunciados, podemos conceber esses sujeitos como sujeitos vulneráveis, que estão à mercê da própria sorte, enfrentando cotidianamente todos os tipos de problemas e conflitos, eles estão mais para sujeitos que sobrevivem do que de fato vivem.

É importante voltar o olhar para o papel da mídia, pois ela participa de modo bastante ativo na construção de representações possíveis acerca desses sujeitos. É relevante destacar a importante função que a mídia ocupa nesse cenário, de expor e descrever situações que causam certo desconforto, voltando a atenção, mesmo que momentaneamente, para os diversos problemas que os indígenas ainda enfrentam. Em segundo plano, se questiona o demasiado interesse pela produção e veiculação de notícias violentas, que possuem detalhes de homicídios, suicídios, agressões contra a mulher e de violência em geral. Essas notícias não são representativas dos povos indígenas, mas do que se veicula a respeito deles na mídia, sendo construído, no imaginário social, um cenário caótico e problemático. A escolha de dessas temáticas para noticiar e informar acaba por construir "uma imagem fragmentada do espaço público, uma visão adequada aos objetivos da mídia, mas bem afastada de um reflexo fiel" (CHARAUDEAU, 2013, p. 20). Em situações que a questão indígena toma forma nas discussões, muito provavelmente são a esses enunciados que os imaginários recorrem, construindo um sujeito indígena como "coitado, à margem, alcoólatra, drogado, violento".

Fernandes (2012), assentado nos pressupostos de Michel Foucault (2002), considera que os sujeitos se reconhecem e são subjetivados sob determinações históricas e sociais, e seu processo de subjetivação tem como base a exterioridade. Deste modo, para o sujeito indígena, sua história é a de pertença a grupos sobreviventes que, historicamente, enfrentaram guerras, perseguições, escravizações e que tiveram suas terras tomadas, seus valores e costumes 
profundamente alterados e desvalorizados. Passaram de povos considerados caçadores e fortes a vulneráveis.

Os sujeitos indígenas têm sua subjetividade constituída por esses discursos midiáticos que, nesse caso, reverberam reiteradamente as palavras "violência, abuso, vítima, homicídios, suicídios, mortalidade", palavras estas que possuem pertença a campos semânticos negativos e pejorativos. A partir de termos como "registros, relatórios e taxas", utilizados nos enunciados 1 e 2, é possível fazer correlação com algumas imagens atribuídas a eles, pois, no imaginário coletivo e de senso comum, os indígenas ainda são "registrados, relatados e taxados" como sujeitos violentos, agressivos, suicidas e homicidas.

Estes sujeitos estão inseridos em um cenário em que sua forte conexão com a terra e com a natureza tem sido confrontada pelas culturas e práticas do homem não indígena da sociedade ocidental, suas tradições entram em constante conflito com o modo de produção capitalista. Os sujeitos indígenas vivem, em sua maioria, em constante luta por terras e, portanto, em situação de violência. Nesse cenário, eles são estigmatizados, se encontram no limiar de culturas, que se esbarram e se transformam no contato de uma com a outra, tentando assimilar o que é novo, o que é benéfico ou não. Essas imagens que são cristalizadas no imaginário social vêm à tona quando o tema pede discussão.

Os sujeitos indígenas são ao mesmo tempo representados estereotipadamente pela mídia, como também tem sua subjetivação sendo alicerçada cada vez mais nessas imagens disformes. Os povos originários indígenas, sua cultura, língua e costumes não só são desvalorizados como são alvos de preconceitos cotidianos que, quando circundam pela cidade de Dourados, as situações descritas por Goffman (2019), sobre a estigmatização, são facilmente identificáveis. Os indígenas são recebidos em lojas, bares e mercados e tão logo categorizados e estigmatizados. E em uma tentativa de serem mais bem aceitos, negam a si próprios como forma de sobrevivência.

O contato secular com as práticas do sujeito não indígena resulta em aldeias superlotadas, já que seus territórios foram condensados a partir da colonização, e com uma gama de problemas novos que desafiam a competência da liderança tradicional, as reservas tornaram-se lugares muito difíceis para se viver. Nesse contexto, muitas famílias abandonam as aldeias e saem à procura de outras áreas, já ocupadas no passado por parentes, como aponta Chamorro (2015).

Os dados trazidos no enunciado 2 apontam que a cidade de Dourados ocupa a segunda posição no ranking de violência de todos os tipos contra mulheres indígenas. E desde 
2012, Dourados é a cidade que mais possui casos de violência sexual contra mulheres indígenas do Brasil.

Diante do exposto, se faz relevante problematizar a questão da mulher, que historicamente sofre pelas opressões do machismo e do patriarcado, que se intensificam ainda mais nessa aparentemente "terra sem lei", sendo alvo de violência doméstica, de abusos sexuais e psicológicos. A mulher é subjetivada como aquela que sofre a violência, que seria frágil em relação ao homem. Ela possui uma dupla sujeição, por ser mulher e ser indígena. Se ainda são negados alguns papeis sociais às mulheres não indígenas, que vêm avançando na luta pela conquista e permanência de direitos, a mulher indígena sofre duplamente essas opressões, por questões de gênero e raça.

Exatamente pelo fato de que os valores e os padrões culturais destoam de uma cultura para outra, problematizar a violência contra a mulher indígena pode ser ainda mais difícil. Historicamente, homens e mulheres indígenas possuíam relações complementares, pois as tarefas eram divididas igualmente. Os papeis sociais de homens e mulheres na aldeia e dentro do núcleo familiar possuíam o mesmo status (VIANA; SOUZA; ZIMMERMAN, 2014).

Um dos aspectos considerados pertinentes nos casos de violência doméstica, introduzida com as novas práticas e alterações culturais provindas do contato com o não indígena, é a dependência financeira da mulher casada em relação a seu marido, dependência essa considerada forçada e histórica, já que essa visão de "dependência" não existia anteriormente, porque todos os afazeres possuíam divisões igualitárias entre marido e mulher. Esse é um dos fatores que fazem com que a mulher indígena que sofre de violência permaneça com seu esposo, e mesmo sofrendo cotidianamente, ela não vê alternativa senão a continuar no relacionamento abusivo. Essa questão é conhecida por agentes públicos que até tentam promover a independência da mulher por meio da produção e venda do artesanato local, prática muito comum no cenário indigenista.

Diante das considerações apresentadas, foi possível perceber que as construções midiáticas acerca do que seja o sujeito indígena têm se baseado, neste caso, em reiterações de papeis sociais estereotipados e estigmatizados.

A mídia é um importante veículo social que contribui significativamente com seu papel de denunciar e informar, de representar e dar voz; no entanto, ao informar apenas notícias ruins, acaba por cristalizar e subjetivar o sujeito indígena, dando-lhes papeis sociais à margem. A mesma mídia que trata das questões negativas opta por silenciar outros assuntos indígenas, como o ingresso de estudantes indígenas nas instituições de ensino superior, sua luta por terras, o descaso dos órgãos públicos, a autonomia da mulher indígena etc. 


\subsection{Resistência indígena na região do MS}

\section{Enunciado 3}

No terceiro dia de bloqueio, caminhões parados há mais de 48 horas são liberados (Jornal Dourados News - André Bento, 3 de outubro de 2019)

Veículos pesados que estavam há mais de 48 horas parados no bloqueio da MS156 entre Dourados e Itaporã foram liberados na manhã desta quinta-feira (3) após negociação da PMR (Polícia Militar Rodoviária) com os manifestantes. Encampado por moradores da Aldeia Jaguapiru, o protesto é motivado pelo corte do transporte escolar para universitários promovido pela prefeitura.

Ao Dourados News, Queila Viana da Silva, estudante do curso de Letras da UEMS (Universidade Estadual de Mato Grosso do Sul), informou ainda no primeiro dia de protesto que 150 estudantes têm sido prejudicados pela falta do transporte escolar. "Já faz mais de um mês que a gente tenta negociar com a prefeita e ela não libera o ônibus. É garantido por lei e a gente quer o nosso ônibus, porque está tirando a dignidade de muitos acadêmicos, está tirando o direito do sonho deles. Já passou um mês, estão praticamente reprovados por falta. Estamos sendo muito prejudicados por isso, tentamos o diálogo, mas não obtivemos resposta. O bloqueio vai permanecer até que ela traga uma resposta concreta para nós, não queremos mais blábláblá”, assegurou.

\section{Enunciado 4}

\section{Confronto próximo a "área de tensão" deixa feridos em Dourados. (Jornal Dourados News, por Adriano Moretto e Osvaldo Duarte - dia 03 de janeiro de 2020)}

Confronto próximo a região da Perimetral Norte, em Dourados, deixou feridos na manhã desta sexta-feira (3/1). O local é alvo de disputa por terra entre produtores rurais e indígenas há mais de um ano. Pelo menos quatro pessoas teriam sido baleadas, incluindo indígenas e seguranças que prestam serviço nessa área. Fogo também foi ateado na região.

A escolha do enunciado 3 se dá porque está presente em uma notícia que destoa das inúmeras outras encontradas nos jornais, após páginas e páginas de representações de um sujeito que sofre, com descrições das mazelas encontradas nas aldeias, esta possui um tom diferente, de uma tentativa do sujeito de resistir. A aldeia Jaguapiru, citada no enunciado 3, fica localizada na região da cidade de Dourados.

Em comparação aos enunciados 1 e 2, os enunciados 3 e 4 nos apresentam sujeitos que não são passivos, eles estão tentando fazer algo. Em um momento estão bloqueando as estradas, construindo barricadas para impedir a passagem de automóveis, encontrando, certamente, nesta ação, uma forma de lutar pela conquista e permanência dos seus direitos, e 
Luiz Fernando Roecker; Sílvia Mara Melo. O sujeito indígena subjetivado pela mídia na região do Mato Grosso do Sul.

em outro, estão ocupando terras, tentando ter acesso a elas. Eles podem ser representados como sujeitos da resistência, aqueles que em meio aos diversos problemas que enfrentam cotidianamente, estão resistindo e sobrevivendo. Encaramos como uma atitude positiva o fato de os sujeitos indígenas estarem lutando por seus direitos (estabelecidos legalmente ou não), numa espécie de mobilização política e social totalmente válida e justificável.

Se tomarmos um termo de Foucault em Vigiar e Punir (2011), podemos considerar que os sujeitos-indígenas da resistência não são sujeitos "dóceis" e "disciplinados" e não estão dispostos a aceitar as condições que lhes foram impostas pelas conjunturas sociais, históricas e políticas. As palavras "manifestante", "protesto" e "confronto" utilizadas nos enunciados 3 e 4 materializam e expressam significados que demonstram desconforto, indignação e não aceitação das situações vivenciadas pelos indígenas.

Foucault (2011, p. 133) denomina "disciplina" o método que "permite o controle minucioso das operações do corpo, que realiza a sujeição constante de suas forças e lhes impõe uma relação de docilidade-utilidade". Para o autor, os métodos disciplinares existiram nos conventos, nos exércitos, nas oficinas. Nas palavras de Foucault (2011, p. 133), “a disciplina fabrica assim corpos submissos e exercitados, corpos dóceis”. Desse modo, pode-se conceber que não são sujeitos disciplinados, silenciados, mas que estão resistindo aos desmandos do poder público local que negam seus direitos.

Questionamo-nos se a motivação da veiculação dessas notícias está relacionada ao “exercício da cidadania” proposto por Charaudeau (2013) ou se segue a mesma lógica de noticiar eventos conflituosos e violentos que envolvem indígenas. É necessário destacar que os enunciados 3 e $\mathbf{4}$ também se materializam na esfera de veiculação dos enunciados $\mathbf{1}$ e $\mathbf{2}$, e como já se constituiu um imaginário coletivo a respeito dos sujeitos indígenas, é possível que muitos leitores dessa mídia encarem essas atitudes de resistência não apenas como forma de se tornarem visíveis em suas lutas, mas como sujeitos conflituosos que promovem a desordem na cidade, pois previamente a mídia colaborou na criação de representações em que os indígenas são considerados violentos, invasores de terras alheias e desordeiros.

Desse modo, nos enunciados 3 e $\mathbf{4}$, eles estariam apenas "impedindo a circulação do trânsito e invadindo propriedades privadas", somando ainda mais sentidos negativos e pejorativos à identidade e à cultura indígena. Ainda que as notícias apontem para outras ações pertinentes aos indígenas, as formações sociais imaginárias estabelecidas reverberam uma subjetividade para esses povos, a de que são violentos, perigosos, desordeiros etc. 


\section{Considerações finais}

A partir das considerações realizadas, podemos concluir que os sujeitos indígenas são representados de modo estereotipado pelas mídias, e quando não o são, as formações imaginárias e coletivas estabelecidas e reiteradas paulatinamente pelas mídias ganham espaço e vez para pensar novamente estes sujeitos como ocupantes de posições não desejáveis socialmente. A constante recorrência a notícias de teor conflituoso e violento corrobora a construção de uma imagem distorcida sobre esses povos. Essas imagens e representações incidem no processo de subjetivação e de constituição do sujeito, conforme apontam Fernandes (2012) e Foucault (2002).

Destacamos o importante papel da mídia de denunciar os descasos enfrentados pelos sujeitos indígenas, dar voz e espaço para suas causas, porém se faz necessário refletir a respeito da forma mais benéfica e respeitosa de se fazer isso, sem contribuir ainda mais para a construção de visões e representações deturpadas dos grupos e povos indígenas. É necessário reconhecer o gigantesco preconceito ainda existente na região de Dourados, seja ele implícito ou explícito, mas que de igual maneira deve ser combatido. Dentre as possibilidades de enfrentamento, recorremos aos princípios de uma mídia que pode atuar a serviço do jornalismo democrático, imparcial, em benefício dos cidadãos, em consonância com os trabalhos de Charaudeau (2013) e Peruzzo (2005).

Quando nos propomos pensar e discutir os povos originários indígenas, são a partir de remissões históricas que poderemos melhor compreendê-los, pois os diversos processos de colonização ainda refletem em questões da atualidade, conforme historicizam Chamorro (2015) e Moura e Acçolini (2015). A partir da compreensão destes processos históricos, espera-se menor estigmatização e maior entendimento das situações enfrentadas pelos povos indígenas, num caminho que visa a diminuição das diversas taxas e índices apontados nos enunciados que este trabalho analisou, em que as ações de combate e prevenção devem ter protagonismo de órgãos governamentais. O trabalho não objetivou encerrar nenhuma discussão ou pauta, mas pretende ampliá-las, em um constante apoio às lutas e resistências indígenas. 


\section{Referências}

ARAÚJO, Valéria. Em aldeia mais perigosa do País para mulheres, força indígena se une contra violência doméstica. O Progresso. Dourados, Mato Grosso do Sul. 4 de dezembro de 2019. Disponível em: <http://abre.ai/beAd>. Acesso em: 28 jan. 2020.

AZEVEDO, Marta Maria. Diagnóstico da População Indígena no Brasil. Ciência e Cultura, São Paulo, v. 60, n. 4, p. 19-22, 2008. Disponível em: <http://cienciaecultura.bvs.br/pdf/cic/v60n4/a10v60n4.pdf>. Acesso em: 9 dez. 2020.

BENTO, André. No terceiro dia de bloqueio, caminhões parados há mais de 48 horas são liberados. Dourados News. Dourados, Mato Grosso do Sul. 3 de outubro de 2019. Disponível em: <http://abre.ai/beAj>. Acesso em: 29 fev. 2020.

CHAMORRO, Graciela. Povos indígenas guarani falantes no atual Estado deMato Grosso do Sul (séculos XVI-XXI). In: CHAMORRO, G.; COMBÈS, I. (org.). Povos indígenas em Mato Grosso do Sul: história, cultura e transformações sociais. Dourados, MS: Editora da UFGD, 2015, p. 293-322.

CHARAUDEAU, Patrick. Discurso das mídias. Tradução Angela. M. S. Corrêa. 2. ed. São Paulo: Contexto, 2013.

FERNANDES, Cleudemar Alves. Análise do Discurso: reflexões introdutórias. 2. ed. São Carlos: Claraluz, 2008.

FERNANDES, Cleudemar Alves. Discurso e Sujeito em Michel Foucault. São Paulo: Intermeios, 2012

FOUCAULT, Michel. História da loucura. Tradução José Teixeira Coelho Netto. São Paulo: Perspectiva, 2002.

FOUCAULT, Michel. A hermenêutica do sujeito. Tradução Márcio Alves da Fonseca e Salma Tannus Muchail. 2. ed. São Paulo: Martins Fontes, 2006.

FOUCAULT, Michel. A arqueologia do saber. Tradução Luiz Felipe Baeta Neves. 7. ed. Rio de Janeiro: Forense universitária, 2008.

FOUCAULT, Michel. Vigiar e Punir: história da violência nas prisões. 39. ed. Tradução Raquel Ramalhete. Petrópolis: Rio de Janeiro, 2011.

FOUCAULT, Michel. A ordem do discurso. Aula inaugural no Collège de France, pronunciada em 2 de dezembro de 1970. Tradução Laura Fraga de Almeida Sampaio. 24. ed. São Paulo: Edições Loyola, 2014.

GOFFMAN, Erving. Estigma - notas sobre a manipulação da identidade deteriorada. Tradução Márcia Bandeira de Mello Leite Nunes. 4. ed. Rio de Janeiro: LTC, 2019.

IBGE. Instituto Brasileiro de Geografia e Estatística - IBGE. Indígenas - Estudos Especiais. Disponível em: https:<//indigenas.ibge.gov.br/estudos-especiais-3.html $>$. Acesso em: 10 maio 2020. 
IBGE. Instituto Brasileiro de Geografia e Estatística - IBGE. Censo Demográfico 2010 características gerais dos Indígenas: resultados do universo. Rio de Janeiro: 2010, p. 245. Disponível em: <https://biblioteca.ibge.gov.br/visualizacao/periodicos/95/cd_2010_indigenas_universo.pdf>. Acesso em: 9 dez. 2020.

MELO, Iran Ferreira de. Análise do Discurso e Análise Crítica do Discurso: desdobramentos e interseções. Letra Magna - Revista Eletrônica de Divulgação Científica em Língua Portuguesa, Linguística e Literatura Letra Magna, Ano 5, n. 11, $2^{\circ}$ semestre de 2009. Disponível em: <http://www.letramagna.com/adeacd.pdf>. Acesso em: 9 mar. 2020.

MORETTO, Adriano; DUARTE, Osvaldo. Confronto próximo a "área de tensão" deixa feridos em Dourados. Dourados News. Dourados, Mato Grosso do Sul. 3 de janeiro de 2020. Disponível em: <http://abre.ai/beAk>. Acesso em: 6 jan. 2020.

MOURA, Noêmia; ACÇOLINI, Graziele. Os terena em Mato Grosso do Sul. In: CHAMORRO, G.; COMBÈS, I. (org.). Povos indígenas em Mato Grosso do Sul: história, cultura e transformações sociais. Dourados, MS: Editora da UFGD, 2015, p. 249-266.

MUSSALIM, Fernanda. Análise do Discurso. In: MUSSALIM, F.; BENTES, A. C. (org.). Introdução à Linguística. v. 2, 6. ed. São Paulo: Cortez Editora, 2009.

PAGLIARO, Heloísa; AZEVEDO, Marta Maria; SANTOS, Ricardo Ventura. Demografia dos Povos Indígenas no Brasil: um panorama crítico. In: PAGLIARO, H.; AZEVEDO, M. M.; SANTOS, R. V. (org.). Demografia dos povos indígenas no Brasil. Rio de Janeiro: Editora Fiocruz e ABEP, 2005. Disponível em: <http://www.precog.com.br/bctexto/obras/pagliaro-9788575412541.pdf>. Acesso em: 9 dez. 2020. DOI: https://doi.org/10.7476/9788575412541

PERUZZO, Cicilia M. Krohling. Mídia regional e local: aspectos conceituais e tendências. Comunicação \& Sociedade, São Bernardo do Campo: Póscom-Umesp, ano 26, n. 43, p. 6784, $1^{\circ}$ sem. 2005. DOI: https://doi.org/10.15603/2175-7755/cs.v26n43p67-84

RESERVA de Dourados tem maior taxa de suicídio do país. Dourados News. Dourados, Mato Grosso do Sul. 9 de janeiro 2018. Disponível em: <http://abre.ai/bez5>. Acesso em: 17 mar. 2020.

SATHLER, Corando Neves. Formações subjetivas: o sujeito à luz da teoria dos discursos. Dourados, MS: Editora da UFGD, 2016.

VIANA, Ana E. A.; SOUZA, Laurine S. O.; ZIMMERMAN, Tânia R. Apontamentos sobre gênero e violência contra mulheres indígenas Kaiowa e Guarani em Amambai, MS (20072014). Tellus, Campo Grande, MS, ano 14, n. 27, p. 117-128, jul./dez. 2014. DOI: https://doi.org/10.20435/tellus.v0i27.311

Recebido em: 4 de agosto de 2020

Aceito em: 4 de dezembro de 2020 